\title{
The uptake of active surveillance for the management of prostate cancer: A population-based analysis
}

\author{
Patrick O. Richard, MD, ,1,2 Shabbir M.H. Alibhai, MD, ${ }^{3}$ Tony Panzarella, MD, Laurence Klotz, MD, ${ }^{, 5}$ \\ Maria Komisarenko, MD; Neil E. Fleshner, MD;' David Urbach, MD; ${ }^{6}$ Antonio Finelli, MD'
}

'Division of Urology, Departments of Surgery and Surgical Oncology, Princess Margaret Cancer Centre, University Health Network and the University of Toronto; 2 Division of Urology, Department of Surgery, Centre Hospitalier Universitaire de Sherbrooke and the University of Sherbrooke, Sherbrooke, QC, Canada; ${ }^{3}$ Department of Medicine, University Health Network and the University of Toronto; ${ }^{4 B i o s t a t i s t i c s ~}$ Department, Princess Margaret Hospital, University Health Network and the University of Toronto; ${ }^{5}$ Division of Urology, Sunnybrook Health Sciences Centre and the University of Toronto; ${ }^{6}$ Department of Surgery, University Health Network and the University of Toronto; Toronto, ON, Canada

Cite as: Can Urol Assoc J 2016;10(9-10):333-8. http://dx.doi.org/10.5489/cuai.3684 Appendices published online as of October 17

\section{Abstract}

Introduction: Active surveillance (AS) is a strategy for the management of low-risk prostate cancer (PCa). However, few studies have assessed the uptake of AS at a population level and none of these were based on a Canadian population. Therefore, our objectives were to estimate the proportion of men being managed by AS in Ontario and to assess the factors associated with its uptake.

Methods: This was a retrospective, population-based study using administrative databases from the province of Ontario to identify men $\leq 75$ years diagnosed with localized PCa between 2002 and 2010. Descriptive statistics were used to estimate the proportion of men managed by AS, whereas mixed models were used to assess the factors associated with the uptake of AS.

Results: 45691 men met our inclusion criteria. Of these, 18\% were managed by AS. Over time, the rates of AS increased significantly from $11 \%$ to $21 \%(p<0.001)$. Older age, residing in an urban centre, being diagnosed in the later years of the study period, having a neighborhood income in the highest quintile, and being managed by urologists were all associated with greater odds of receiving AS. Conclusions: There has been a steady increase in the uptake of AS between 2002 and 2010. However, only 18\% of men diagnosed with localized PCa were managed by AS during the study period. The decisions to adopt AS were influenced by several individual and physician characteristics. The data suggest that there is significant opportunity for more widespread adoption of AS.

\section{Introduction}

Since the introduction of prostate-specific antigen (PSA)based screening, there has been an increase in the incidence of prostate cancer (PCa) ${ }^{1,2}$ However, this increase is mostly driven by an increase in the diagnosis of clinically insignificant cancers. ${ }^{3}$ Thus, the management of PCa has been associated with considerable overtreatment. Active sur- veillance (AS) has been proposed as a strategy to decrease overtreatment ${ }^{4-10}$ and is now recognized as a management option by a number of evidence-based guidelines. ${ }^{11-13}$

Although several prospective series have reported on its safety, ${ }^{4-10}$ few studies have reported on the uptake of AS at a population level. ${ }^{14-23}$ No previous population-based study has evaluated the proportion of men being managed by AS in Canada. In other areas of PCa management, there are significant differences between Canada and other countries. Although a recent single-institution series from the University of Ottawa has examined the treatment patterns of men diagnosed with low-risk $\mathrm{PCa},{ }^{24}$ there remains a need to better understand the rates of AS use and the factors related to its adoption, outside of single-institution series. We hypothesized that the rates of AS increased throughout the study period.

\section{Methods}

\section{Participants}

This was an institutional review board-approved, population-based, retrospective study that identified, using administrative databases, men aged $18-75$ years who were diagnosed with adenocarcinoma of the prostate between January 1, 2002 and December 31, 2010 in Ontario. We excluded men whose diagnostic procedure was not a transrectal ultrasound-guided biopsy (TRUSB) or a transurethral resection of the prostate (TURP). Men who died or who received primary medical or surgical castration and/or palliative radiotherapy within the first year after diagnosis were also excluded.

All medical procedures in Ontario are reimbursed by a single payer system (Ontario Health Insurance Plan [OHIP]). All OHIP fee codes used are listed in Appendix 1 (available at www.cuaj.ca). We linked these OHIP codes to the Ontario Cancer Registry, the Registered Persons Database, and the Ontario Drug Database to identify the management 
Richard et al.

of subjects diagnosed with PCa (data cutoff December 31, 2013). As there are no codes to differentiate between radiotherapy given with curative or palliative intent, we defined the latter as therapy given within one month or $\geq 6$ months after castration. All localized PCa were included in this study, regardless of the risk-group stratification. ${ }^{25}$

\section{Treatment groups}

Subjects were allocated to one of four groups. The ones who received definitive therapies (i.e., surgery, external beam radiotherapy, or brachytherapy) within the first year following diagnosis without a second TRUSB beforehand were allocated to the definitive treatment group. The remaining men were considered to be in the expectant/observation group that was then subdivided into AS, watchful waiting (WW), and delayed treatments.

The AS group was composed of individuals who had undergone a second TRUSB (confirmatory biopsy) following diagnosis, before any definitive treatments were instituted or before castration. The remaining patients were allocated to the WW/ delayed treatment group, which consisted of men who had no subsequent repeat TRUSB or treatments other than castration or palliative radiotherapy (WW) and of men who received definitive therapies $>12$ months after diagnosis (delayed treatment).

\section{Variables}

Using the databases, we determined individual-, physicianand institution-level characteristics. The individual-level characteristics included age at diagnosis, year of diagnosis, neighbourhood income quintile (hereinafter referred to as simply income quintile), and the area of residency. The Aggregated Diagnosis Groups (ADG) score, derived from the Johns Hopkins University Adjusted Clinical Groups CaseMix system, was used to measure comorbidity. ${ }^{26}$

Physician- and institution-level characteristics included the treating physician' speciality and his/her annual new PCa-related case volume, as well as the type of treating centre and its annual new PCa-related case volume. The treating physician was defined as the physician who claimed the most PCa-related visits for each individual during the first year after diagnosis, while the treating institution was defined as the institution where the patient received the majority of his PCa care during the same timeframe.

\section{Outcomes}

The primary outcome was to determine the proportion of men with localized PCa managed by AS during the study period. Secondary outcomes were to estimate the uptake of AS over time and to estimate the characteristics associated with the uptake of AS.

\section{Statistical analysis}

Descriptive statistics were used to describe the cohort. Medians and interquartile range (IQR) were reported for continuous variables, while proportions were used to report categorical variables. Medians were compared using Wilcoxon or the Kruskal-Wallis sum of rank tests, where appropriate. Chi-squared analyses were used to compare categorical variables, while the Chi-square test for trend was used to estimate whether there was a significant increase in the adoption of AS over time.

Baseline characteristics associated with the adoption of AS were evaluated using a non-linear mixed model adjusted for a priori defined covariates based on previous studies (Appendix 2 at www.cuaj.ca) and adjusted for physicianand institution-level clusters assuming cross-classified data (i.e., physicians could work in more than one institution). ${ }^{27}$ Estimates in the multivariable models are reported as odds ratios (ORs) with corresponding 95\% confidence intervals (Cls). Physician- and institution-attributable intra-class correlations were obtained by calculating the ratio of the between-cluster variance to the total variance..$^{28}$ Five models specified for each of the outcomes were constructed to account for explained and unexplained variances.

Sensitivity analyses were also performed using three different definitions to identify men managed by AS (Appendix 3 at www.cuaj.ca). All statistical analyses were performed using SAS 9.4 and $\mathrm{R}$ version 3.1.3 statistical software. All analyses were two-sided, and $p$ values less than 0.05 were considered statistically significant, with the exception of when multiple comparisons were required, at which time a Bonferroni correction was used..$^{29}$

\section{Results}

A total of 79498 men diagnosed with PCa between 2002 and 2010 were identified, of which 33807 were excluded for various reasons (Appendix 4 at www.cuaj.ca). The final cohort was composed of 45691 men. The characteristics of these men and their treating physicians $(n=424)$ and institutions $(n=215)$ are listed in Table 1.

Of the men included in this study, $70 \%(n=31819)$ opted for upfront definitive therapies, whereas the remaining patients $(n=13872)$ were managed, at least initially, expectantly. Of these, $58 \%(n=8079), 33 \%(n=4570)$, and $9 \%(n=1223)$ were managed by AS, WW, and delayed definitive treatment, respectively. The proportion of men managed by AS represented $18 \%$ of the total cohort (Table $2)$. Over time, the proportion of men managed expectantly increased significantly $(\mathrm{p}<0.001$; Appendix 5 at www.cuaj. ca). This increase was mainly driven by an increase in the number of men managed by AS, which increased from $11 \%$ in 2002 to $21 \%$ in 2010 ( $p<0.001)$. 


\begin{tabular}{|c|c|c|c|c|c|}
\hline \multirow[b]{2}{*}{ Variables } & \multicolumn{5}{|c|}{ Expectant therapy ( $n=13$ 872) } \\
\hline & $\begin{array}{c}\text { Total } \\
\text { ( } \mathrm{n}=45691) \\
\mathrm{n}(\%)\end{array}$ & $\begin{array}{c}\text { Active surveillance } \\
(\mathrm{n}=\mathbf{8 0 7 9 )} \\
\mathrm{n}(\%)\end{array}$ & $\begin{array}{l}\text { Watchful waiting } \\
(n=4570) \\
n(\%)\end{array}$ & $\begin{array}{c}\text { Delayed treatment } \\
(n=1223) \\
n(\%)\end{array}$ & $\begin{array}{c}\text { Definitive treatment } \\
\text { (n=31 819) } \\
n(\%)\end{array}$ \\
\hline & \multicolumn{5}{|c|}{$\begin{array}{ll}\text { Individual-level characteristics } \\
\end{array}$} \\
\hline \multicolumn{6}{|l|}{ Year of diagnosis } \\
\hline 2002-2004 & $12554(28)$ & $1637(28)$ & $1204(26)$ & $396(32)$ & $9713(29.3)$ \\
\hline 2005-2007 & 15937 (25) & 2917 (33) & 1497 (33) & $430(35)$ & $11093(34.9)$ \\
\hline 2008-2010 & $17200(38)$ & 3525 (39) & $1869(41)$ & $397(33)$ & 11409 (35.9) \\
\hline \multicolumn{6}{|l|}{ Age group (years old) } \\
\hline Less or equal to 55 & $6148(14)$ & $948(12)$ & $343(8)$ & $120(10)$ & $4737(14.9)$ \\
\hline $56-65$ & $19430(43)$ & $3369(42)$ & $1337(29)$ & $472(39)$ & $14252(44.8)$ \\
\hline $66-75$ & 20113 (44) & $3762(47)$ & $2890(63)$ & $631(52)$ & $12830(40.3)$ \\
\hline \multicolumn{6}{|l|}{ Diagnostic procedure } \\
\hline Biopsy & 43670 (96) & 7975 (99) & $3232(71)$ & 1084 (89) & 31379 (71.9) \\
\hline TURP & 2021 (4) & $104(1)$ & $1338(29)$ & $139(11)$ & $440(21.8)$ \\
\hline ADG score, median (IQR) & $16(7-22)$ & $16(7-23)$ & $17(9-26)$ & $17(8-23)$ & $15(7-22)$ \\
\hline \multicolumn{6}{|l|}{ Survival status } \\
\hline Alive & 42592 (93) & $7746(96)$ & $3982(87)$ & $1127(92)$ & 29737 (94) \\
\hline Died & $3099(7)$ & $333(4)$ & $588(13)$ & $96(8)$ & $2082(7)$ \\
\hline Prostate cancer death & $396(0.9)$ & $13(0.2)$ & $45(1)$ & $15(1)$ & $323(1)$ \\
\hline \multicolumn{6}{|l|}{ Income quintile } \\
\hline First (lowest) & $6428(14)$ & $1061(13)$ & $778(17)$ & $189(16)$ & 4400 (14) \\
\hline Second & 8408 (18) & $1442(18)$ & $923(20)$ & $238(20)$ & 5805 (18) \\
\hline Third & $8974(20)$ & 1485 (18) & $893(20)$ & $244(20)$ & $6352(20)$ \\
\hline Fourth & $9937(22)$ & $1734(22)$ & $928(20)$ & $247(20)$ & $7028(22)$ \\
\hline Fifth (highest) & $11791(26)$ & $2327(29)$ & $1025(22)$ & $302(25)$ & $8137(26)$ \\
\hline \multicolumn{6}{|l|}{ Rural } \\
\hline Yes & $6653(15)$ & $817(10)$ & $709(16)$ & $211(17)$ & $4916(16)$ \\
\hline \multirow[t]{2}{*}{ No } & $39003(85)$ & $7257(90)$ & 3857 (84) & $1012(83)$ & $26877(85)$ \\
\hline & \multicolumn{5}{|c|}{ Physician-level characteristics } \\
\hline \multicolumn{6}{|l|}{ Type of primary physician } \\
\hline Urologist & 30552 (67) & $5323(66)$ & $3866(85)$ & $1030(84)$ & $20333(64)$ \\
\hline Radiation oncologist & 14986 (33) & 2705 (34) & $627(14)$ & $190(16)$ & $11464(36)$ \\
\hline \multicolumn{6}{|l|}{ Physician volume per year } \\
\hline 1st quartile (lowest) & $11278(25)$ & $1799(22)$ & 1724 (38) & $450(37)$ & $7305(23)$ \\
\hline 2nd quartile & $11327(25)$ & $1794(22)$ & $1323(29)$ & $358(30)$ & $7852(25)$ \\
\hline 3rd quartile & $11152(24)$ & $1807(22)$ & $813(18)$ & $215(18)$ & $8317(26)$ \\
\hline \multirow[t]{2}{*}{ 4th quartile (highest) } & $11781(26)$ & 2628 (33) & $633(14)$ & $197(16)$ & $8323(26)$ \\
\hline & \multicolumn{5}{|c|}{ Institution-level characteristics } \\
\hline \multicolumn{6}{|l|}{ Institution volume per year } \\
\hline 1st quartile (lowest) & $10954(24)$ & $1522(19)$ & $1389(30)$ & $380(31)$ & $7663(24)$ \\
\hline 2nd quartile & 10824 (24) & $1676(21)$ & $1390(30)$ & $297(24)$ & 7561 (24) \\
\hline 3rd quartile & $11315(25)$ & $1490(18)$ & $892(20)$ & $285(23)$ & $8648(27)$ \\
\hline 4th quartile (highest) & $11497(25)$ & 2952 (37) & $503(11)$ & $192(16)$ & $7850(25)$ \\
\hline \multicolumn{6}{|l|}{ Type of centre } \\
\hline Non-cancer centre & $19444(43)$ & 3147 (39) & $2340(51)$ & $636(52)$ & $13321(42)$ \\
\hline Cancer centre & 25151 (55) & $4493(56)$ & 1735 (38) & $518(42)$ & 18405 (58) \\
\hline
\end{tabular}

In multivariable analysis, older age, residing in an urban centre, being diagnosed in the later years of the study period, having an average neighbourhood income in the highest quintile, and being primarily managed by an urologist were all associated with greater odds of receiving AS. A forest plot summary of the effects of each covariate included in the full model (Model 5) is presented in Fig. 1.

Despite adding all individual-, physician-, and institutionlevel characteristics (Model 5; Appendix 6 at www.cuaj. ca), there remained significant variance between physicians 
Richard et al.

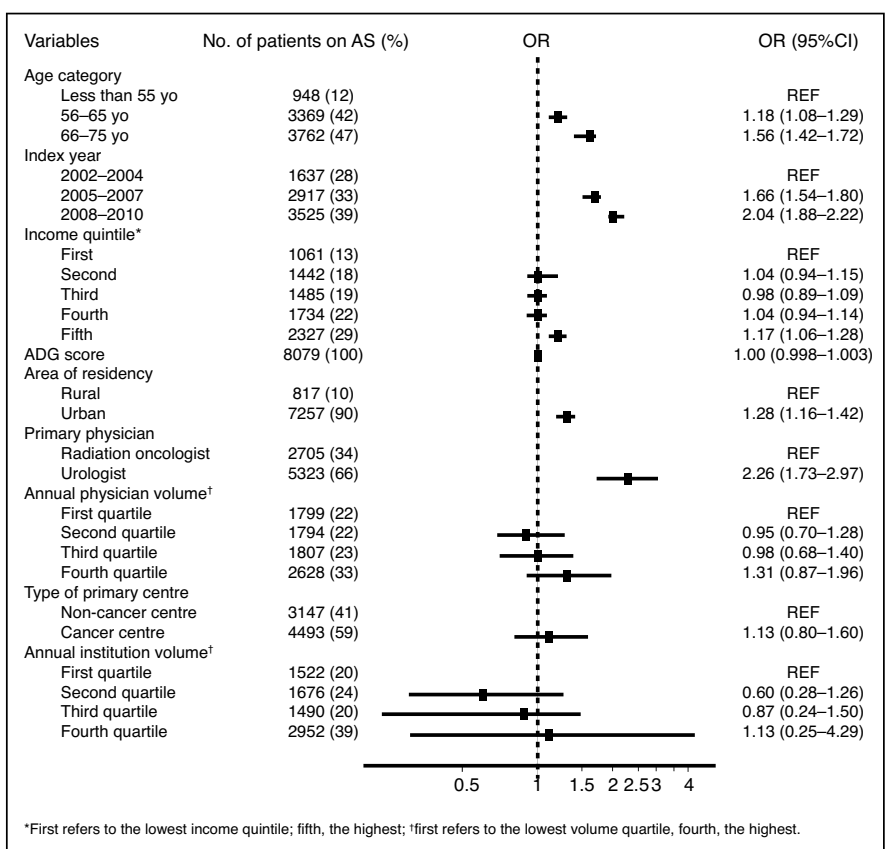

Fig. 1. Forest plot of the odds ratio (OD) for each covariate included in the multivariable analysis - uptake of active surveillance. ADG: Aggregated Diagnosis Groups; AS: active surveillance.

(14\%) and institutions (36\%). All three sensitivity analyses yielded similar results, with the exception of higher comorbidity, which was associated with lower odds of adopting AS using the most liberal definition of AS (Appendix 7 at www. cuaj.ca). There was marked heterogeneity between physicians with regard to the annual proportion of new patients managed by AS. Such heterogeneity was also observed, but to a lesser degree, among the treating institutions (Fig. 2).

\section{Discussion}

In this first Canadian population-based study on AS, $18 \%$ of men diagnosed with localized PCa between 2002 and 2010 were managed by this approach. Since 2002, the use of AS has increased by approximately $1 \%$ per year to reach a rate of $21 \%$ in 2010 . This supports the fact that there is a growing acceptance of AS and likely represents an underestimation of the true proportion of men managed by AS, as the study was not restricted to low-risk PCa. ${ }^{18,20,23}$ Assuming that 50\% of subject had low-risk disease ${ }^{15}$ and that the majority of patients included in our AS group were indeed low-risk, one could postulate that approximately $36 \%$ of patients with low-risk disease were treated by this approach during the study period. These rates were similar to those in other population-based studies, which varied from $10-38 \%{ }^{11,16-}$ $18,20-22$ and in line with the recent single-institution series by Cristea et al. ${ }^{24}$ Differences in study methodology (any-risk cohort vs. low-risk cohort; pooling AS and WW together vs. presenting them separately) and the countries' healthcare systems could explain the divergent rates. Given the similarities of our single-payer healthcare system with that of Sweden, we expected our rates to more closely resemble theirs. ${ }^{19,20}$ In the Swedish study, which excluded men with high-risk diseases, $38 \%$ of Swedish men were managed expectantly between 1998 and $2011 .{ }^{19}$ Rates of AS for the period covering 2007 and 2011 were $59 \%$ and $41 \%$ for the very-low and low- and intermediate-risk groups, respectively. Although a direct comparison with our study is difficult because our cohort included men with high-risk PCa and restricted the age to $\leq 75$ years (the Swedish trial included $10 \%$ of men $>75$ years of age), our rates were comparable.

The factors associated with the uptake of AS in this study were similar to those previously identified. ${ }^{14,18,19}$ Increasing age was strongly associated with a greater likelihood of being managed by AS. This may reflect a degree of discomfort either from physicians, patients, or both, with AS as a safe option for younger and healthier men. Contrary to previous findings, we identified that men living in an urban area and men with the highest income quintile were more likely to receive AS. ${ }^{14,30}$ This may be explained by the universal

\begin{tabular}{|c|c|c|c|c|c|}
\hline Year of diagnosis & $\begin{array}{l}\text { Active surveillance } \\
\text { n (\%) }\end{array}$ & $\begin{array}{c}\text { Watchful waiting } \\
\text { n (\%) }\end{array}$ & $\begin{array}{c}\text { Delayed treatment } \\
\text { n (\%) }\end{array}$ & $\begin{array}{c}\text { Definitive treatment } \\
\text { n (\%) }\end{array}$ & $\begin{array}{c}\text { Total per year } \\
\text { n (\%) }\end{array}$ \\
\hline 2002 & $436(11)$ & $397(10)$ & $135(3)$ & $3044(76)$ & $4012(9)$ \\
\hline 2003 & $545(14)$ & $388(10)$ & $124(3)$ & $2952(74)$ & $4009(9)$ \\
\hline 2004 & $656(15)$ & $419(9)$ & $137(3)$ & $3321(73)$ & $4533(10)$ \\
\hline 2005 & 801 (17) & $433(9)$ & $148(3)$ & $3403(71)$ & $4785(11)$ \\
\hline 2006 & $998(19)$ & $519(10)$ & $133(3)$ & $3716(69)$ & $5366(12)$ \\
\hline 2007 & 1118 (19) & $545(9)$ & 149 (3) & $3974(69)$ & $5786(13)$ \\
\hline 2008 & $1104(20)$ & $567(10)$ & $145(3)$ & $3773(68)$ & $5589(12)$ \\
\hline 2009 & $1215(21)$ & $640(11)$ & $156(3)$ & $3835(66)$ & $5846(13)$ \\
\hline 2010 & $1206(21)$ & $662(12)$ & $96(2)$ & $3701(66)$ & $5765(13)$ \\
\hline Total & 8079 (18) & 4570 (10) & $1223(3)$ & $31819(70)$ & $45691(100)$ \\
\hline
\end{tabular}




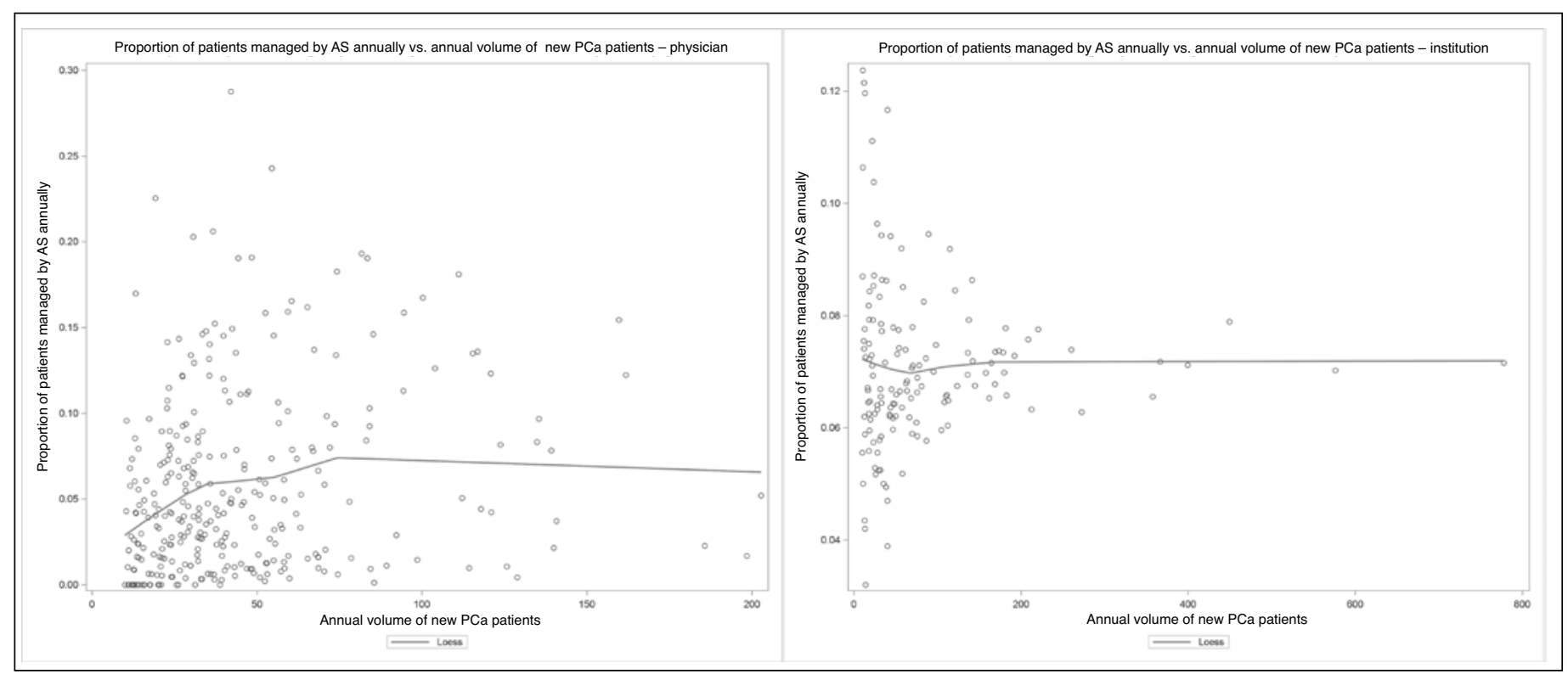

Fig. 2. Scatter plot of the proportion of patients managed by active surveillance annually vs. the annual volume of new prostate cancer patients $(\boldsymbol{A})$ for each physician (minimum of 10 new case/year); (B) for each institution (minimum of 10 new case /year). AS: active surveillance; PCa: prostate cancer.

access to healthcare as opposed to a system in which care is more accessible to higher socio-economic groups. The lack of financial incentive to treat a patient with radical therapies in Canada could also be a plausible explanation as to why men treated in urban centres were more likely to undergo AS. Physicians working in designated cancer centres, which are usually located in urban centres, may have also adopted AS earlier than their other colleagues. Although plausible, this factor was not found to be significantly associated with the uptake of AS in our study.

A major strength of our study is that we used administrative data that encompasses the care of the entire Ontario population. Thus, whereas a study based on Surveillance, Epidemiology, and End Results (SEER) only included Medicare patients $\geq 65$ years of age, our study included all men $\leq 75$ years of age. This study also has several limitations. First, a repeat biopsy was used as a surrogate to identify patients who were managed by AS. Although patients should undergo a confirmatory biopsy (generally within the first year), some refuse. ${ }^{25}$ To partially account for this, we used a minimum look-forward window of three years to identify a repeat biopsy. In addition, we also used several sensitivity analyses to validate our findings. Furthermore, the fact that we could not adjust for risk-group classification represents a significant limitation, as high-risk PCa and, for the most part, intermediate-risk PCa men are not generally considered candidates for AS. Thus, our estimate of the rate of AS is likely conservative and our interpretation of the identified factors associated with the uptake is limited by this confounder.

In spite of these limitations, the study is the first one that attempts to estimate the proportion of men managed with AS in Canada. It supports a greater acceptance of AS as a management option during the study period, but highlights the need for more widespread adoption. In this era of personalized medicine and concerns regarding overtreatment, this study provides a starting point for further studies that should aim toward estimating the ideal proportion of patients (benchmark) with low-risk PCa that should be managed by AS.

\section{Conclusion}

Between 2002 and 2010, 18\% of men diagnosed with localized PCa in Ontario were managed by AS. Over the years, there has been a steady increase in the uptake of AS, which attests to the growing acceptance of this management option. The decision to adopt AS was influenced by several individual and physician characteristics. Further research is underway to better understand the forces influencing care and the rigour with which AS is being provided. The data suggest that there is significant opportunity for more widespread adoption of AS in Ontario.

Competing interests: Dr. Alibhai has received grants from Sanofi. The remaining authors report no competing personal or financial interests.

This paper has been peer-reviewed.

\section{References}

1. American Cancer Society. Cancer Facts and Statistics 2015. Available at http://www.cancer.org/ research/cancerfactsstatistics/index. Accessed August 29, 2016.

2. Public Health Agency of Canada. Public Health Portal. Available at http://www.cancer.ca/en/cancerinformation/cancer-101/canadian-cancer-statistics-publication. Accessed August 29, 2016. 
Richard et al.

3. Draisma $G$, Etzioni $R$, Tsodikov A, et al. Lead time and overdiagnosis in prostate-specific antigen screening: Importance of methods and context. J Natl Cancer Inst 2009;101:374-83. http://dx.doi.org/10.1093/ inci/dip001

4. Dall'Era M, Konety B, Cowan J, et al. Active surveillance for the management of prostate cancer in a contemporary cohort. Cancer 2008;112:2664-70. http://dx.doi.org/10.1002/cncr.23502

5. Eggener $S$, Mueller $A$, Berglund $R$, et al. A multi-institutional evaluation of active surveillance for low-iisk prostate cancer. J Urol 2013;189:S19-26. http://dx.doi.org/10.1016/i.juro.2012.11.023

6. Klotz L, Vesprini D, Sethukavalan $P$, et al. Long-term followup of a large active surveillance cohort of patients with prostate cancer. J Clin Oncol 2015;33:272-7. http://dx.doi.org/10.1200/JC0.2014.55.1192

7. Selvadurai E, Singhera $M$, Thomas $K$, et al. Medium-term outcomes of active surveillance for localized prostate cancer. Eur Urol 2013;64:981-7. http://dx.doi.org/10.1016/i.eururo.2013.02.020

8. Soloway M, Soloway C, Eldefrawy A, et al. Careful selection and close monitoring of low-risk prostate cancer patients on active surveillance minimizes the need for treatment. Eur Urol 2010;58:831-5. http://dx.doi.org/10.1016/i.eururo.2010.08.027

9. Bul $M$, van den Bergh $R$, Zhu $X$, et al. Outcomes of initially expectantly managed patients with low- or intermediate-risk screen-detected localized prostate cancer. BJU Int 2012; 110:1672-7. http://dx.doi. org/10.1111/i.1464-410X.2012.11434.x

10. van den Bergh R, Roemeling S, Roobol M, al. Outcomes of men with screen-detected prostate cancer eligible for active surveillance who were managed expectantly. Eur Urol 2009;55:1-8. http://dx.doi. org/10.1016/i.eururo.2008.09.007

11. Carter H, Albertsen P, Barry M, et al. Early detection of prostate cancer: AUA guideline. J Urol 2013;190:419-26. http://dx.doi.org/10.1016/i.juro.2013.04.119

12. Heidenreich $A$, Abrahamsson $P$, Artibani $W$, al. Early detection of prostate cancer: European Association of Urology recommendation. Eur Urol 2013;64:347-54. http://dx.doi.org/10.1016/i.eururo.2013.06.051

13. Izawa J, Klotz L, Siemens D, et al. Prostate cancer screening Canadian guidelines. Can Urol Assoc J 2011;5:235-40. http://dx.doi.org/10.5489/cuaj.11134

14. Chamie KWS, Hu J. Population-based assessment of determining treatments for prostate cancer. JAMA Oncol 2015;1:60-7. http://dx.doi.org/10.1001/jamaoncol.2014.192

15. Cooperberg M, Broeing J, Carroll P. Time trends and local variation in primary treatment of localized prostate cancer. J Clin Oncol 2010;28:1117-23. http://dx.doi.org/10.1200/JC0.2009.26.0133

16. Cooperberg MR, Carroll PR. Trends in management for patients with localized prostate cancer, 1990-2013. JAMA 2015;314:80-2. http://dx.doi.org/10.1001/jama.2015.6036

17. Filson C, Schroeck $F$, Ye $Z$, et al. Variation in use of active surveillance among men undergoing expectant treatment for early stage prostate cancer. J Urol 2014;192:75-81. http://dx.doi.org/10.1016/i. juro.2014.01.105
18. Hoffman K, Niu J, Shen Y, et al. Physician variation in management of low-risk prostate cancer: A population-based cohort study. JAMA Intern Med 2014;174:1450-9. http://dx.doi.org/10.1001/ jamainternmed.2014.3021

19. Loeb S, Berglund A, Stattin P. Population-based study of use and determinants of active surveillance and watchful waiting for low and intermediate risk prostate cancer. J Urol 2013;190:1742-9. http://dx.doi. org/10.1016/i.juro.2013.05.054

20. Loeb $S$, Folkvalion $Y$, Makarov $D$, et al. Five-year nationwide followup study of active surveillance for prostate cancer. Eur Urol 2015;67:233-8. http://dx.doi.org/10.1016/i.eururo.2014.06.010

21. Mahmood U, Levy L, Nguyen P, et al. Current clinical presentation and treatment of localized prostate cancer in the U.S. J Urol 2014;182:1650-6. http://dx.doi.org/10.1016/i.juro.2014.06.017

22. Weerakoon M, Papa N, Lawrentschuk N, et al. The current use of active surveillance in an Australian cohort of men: A pattern of care analysis from the Victorian Prostate Cancer Registry. BJU Int 2015;115:50-6. http://dx.doi.org/10.1111/bju.13049

23. Womble $\mathrm{P}$, Montie J, Ye Z, et al. Contemporary use of initial active surveillance among men in Michigan with low-risk prostate cancer. Eur Urol 2015;67:44-50. http://dx.doi.org/10.1016/i.eururo.2014.08.024

24. Cristea 0, Lavallée LT, Montroy J, et al. Active surveillance in Canadian men with low-grade prostate cancer. CMAJ 2016 [Epub ahead of print].

25. Mohler J, Armstrong A, Bahnson R, et al. Prostate cancer, version 3.2012: Featured updates to the NCCN guidelines. J Natt Compr Canc Netw 2012;10:1081-7.

26. Austin $P$, van Walraven $C$. The mortality risk score and the ADG score. Two points-based scoring systems for the Johns Hopkins aggregated diagnosis groups to predict mortality in a general adult population cohort in Ontario, Canada. Med Care 201 1;49:940-7. http://dx.doi.org/10.1097/MLR.0b013e318229360e

27. Leckie G. Cross-classified multilevel models - Concepts. LEMMA VLE 2013;12:1-60.

28. Browne $W$, Subramanian $S$, Jones $K$, et al. Variance partitioning in multilevel logistic models that exhibit overdispersion. J R Stat Soc A 2005;168:599-613. http://dx.doi.org/10.1111/i.1467985X.2004.00365.X

29. Cabin RJ, Mitchell RJ. To Bonferroni or not to Bonferroni: When and how are the questions. Bulletin of the Ecological Society of America 2000;81:246-8.

30. Mishra $M$, Shen $X$, Den $R$, et al. Patterns of care for elderly men diagnosed with favourable-risk prostate cancer from 2004 2008: A population-based analysis. Am I Clin Oncol 2013;36:606-11. http://dx.doi. org/10.1097/COC.0b013e318261056c

Correspondence: Dr. Antonio Finelli, Division of Urology, Departments of Surgery and Surgical Oncology, Princess Margaret Cancer Centre, University Health Network and the University of Toronto, Toronto, ON, Canada; antonio.finelli@uhn.ca 